\title{
Correction to: Re-thinking Linkage to Care in the Era of Universal Test and Treat: Insights from Implementation and Behavioral Science for Achieving the Second 90
}

\author{
Michael E. Herce ${ }^{1} \cdot$ Benjamin H. Chi ${ }^{2} \cdot$ Rodrigo C. Liao ${ }^{3} \cdot$ Christopher J. Hoffmann ${ }^{4}$
}

Published online: 31 July 2019

(c) The Author(s) 2019

\section{Correction to: AIDS and Behavior https://doi.org/10.1007/s10461-019-02541-5}

Publisher's Note Springer Nature remains neutral with regard to jurisdictional claims in published maps and institutional affiliations.

The article "Re-thinking Linkage to Care in the Era of Universal Test and Treat: Insights from Implementation and Behavioral Science for Achieving the Second 90", written by Michael E. Herce · Benjamin H. Chi - Rodrigo C. Liao · Christopher J. Hoffmann, was originally published electronically on the publisher's internet portal (currently SpringerLink) on 3rd June 2019 without open access

With the author(s)' decision to opt for Open Choice the copyright of the article changed on 24th July 2019 to (C) The Author(s) 2019 and the article is forthwith distributed under the terms of the Creative Commons Attribution 4.0 International License (http://creativecommons.org/licenses/ by/4.0/), which permits use, duplication, adaptation, distribution and reproduction in any medium or format, as long as you give appropriate credit to the original author(s) and the source, provide a link to the Creative Commons license and indicate if changes were made.

The Original article has been corrected.

The original article can be found online at https://doi.org/10.1007/ s10461-019-02541-5.

Michael E. Herce

michael_herce@med.unc.edu

1 Division of Infectious Diseases, Department of Medicine,

University of North Carolina School of Medicine, 130

Mason Farm Rd. (Bioinformatics), 2nd floor, CB\# 7030,

Chapel Hill, NC 27599-7030, USA

2 Division of Global Women's Health, Department of Obstetrics \& Gynecology, University of North Carolina School of Medicine, Chapel Hill, USA

3 Department of Health Behavior, UNC Gillings School of Global Public Health, Chapel Hill, USA

4 Department of Medicine, Johns Hopkins University School of Medicine and School of Public Health, Baltimore, USA 